\title{
Identifying effective reservoir capacity, water supply, inflow for tradeoff between human and ecological demand
}

\author{
Shan $\mathrm{He}^{1}$, Xin'an Yin ${ }^{1}$, Zhifeng Yang ${ }^{1}$ \\ ${ }^{1}$ State Key Laboratory of Water Environmental Simulation, School of Environment, Beijing Normal University, No. 19 Xinjiekouwai \\ Street, Beijing, China
}

\begin{abstract}
To protect the river ecosystem and sustain ecological flow regime, it's vital to consider environmental flow management in reservoir operation. Many researches try to use more detailed environmental flow management strategies to improve ecological flow regime. However, ecological flow regime not only is influenced by environmental flow management strategy, but also by three kinds of parameters, including reservoir capacity, reservoir inflow and water supply yield. The aim of this paper is to illustrate how ecological flow regime is affected by different reservoir capacities, reservoir inflows and water supply yields and to find a proper reservoir capacity, reservoir inflow or water supply yield under which the optimal ecological flow regime is the best and could not be improved. In this paper, an environmental flow management strategy, which is Four-period release approach (FP), is developed. Besides, social benefit and ecosystem needs are satisfied simultaneously. The results show that changing reservoir capacity, reservoir inflow or water supply yield could improve ecological flow regime.
\end{abstract}

\section{INTRODUCTION}

The protection of environmental flows (e-flows) has been an important part that cannot be ignored in reservoir operation (Vogel et al., 2007; Rheinheimer et al., 2015). One widely used method to protect e-flows is to retain the natural flow regime as much as possible (Shiau and $\mathrm{Wu}$, 2013). The building of dam causes great changes in hydrologic and ecological conditions from natural condition in downstream river (Petts, 2009). The protection of rivers not only needs to remain minimum eflows, but also need to consider ecological flow regime from five aspects: magnitude, timing, duration, frequency, or rate of change of hydrologic flows (Richter and Thomas, 2007). Many research considers ecological flow regime as the mainly optimization objectives to sustain downstream riverine ecosystem healthy. Moreover, water allocation for human demands also affects ecological flow regime (Tsai et al., 2015). To balance human needs and ecosystem healthy, researchers always take more detailed e-flow management strategies and believe they could make better ecological flow regime (Yin et al., 2011). From then on, to sustain ecological flow regime, people commit to study how to detail e-flow management strategies.

According to previous literature, the e-flow management strategies are detailed in three aspects. The first and common way is to detail e-flow requirements in different periods as the flow constraint equation. Richter and Thomas (2007) suggested a dam re-operation project that setting different e-flow limits for specified times, including floods, high flow pulses and low flows, during the process of re-operation and many of the e-flow recommendation are championed by social interests. The second way is to combine different e-flow management strategies into one. Yin et al. (2011) combined three eflow management strategies ("normal," wet, and dry year situations) into a single e-flow strategy to establish a reservoir operating approach that optimized e-flow supply under given water supply demands. The third way is to give specific e-flow released condition for different periods as release rules or ecological objectives. Yin et al. (2012) developed a method to meet downstream ecosystem needs by providing seasonally variable flows for four flow periods, including floods, high flow pulses, low flows and extreme low flows.

But in fact, not all of the rivers need to consider the whole process of flows. E-flow management is not the only way to improve ecological flow regime. The ecological flow regime not only depends on e-flow management strategies, but also depends on the relationship between reservoir capacity, inflow discharge and water supply. Different reservoir capacities, inflow discharges and water supplies with the same e-flow management strategy may also lead to different ecological flow regime.

To give more information about this topic, we study the effect of reservoir capacity, inflow discharge and water supply on ecological flow regime. We take into account a range of reservoir capacity, inflow discharge and water supply and compare the effect of different reservoir capacities, inflow discharges and water supplies on ecological flow regime in reservoir operation. Both ecological requirements and human demands are

\footnotetext{
${ }^{a}$ Corresponding author: jinsefengbao@ $163 . c o m$
} 
considered and their tradeoff is conducted at the same time in reservoir optimization model. In this paper, we established an e-flow management strategy, which is Four-period release approach (FP).

\section{METHODOLOGY}

\subsection{Environmental flow management strategy: Four-period release approach (FP)}

Riverine ecosystems in different periods have different eflow requirements to maintain different corresponding ecological functions. In order to sustain the majority of ecological functions, we need to provide e-flows. Here we incorporate e-flows into reservoir operation model through the assignment of reservoir releases with special e-flows for different periods. According to Mathews and Richter (2007), flows can be divided into four periods on the basis of their magnitudes: floods, high-flow pulses, low flows and extreme low flows.

In flood periods, flows equal to or greater than bankfull discharges. It's reported that bankfull discharges occurred with an average frequency of 1.5 years $(\mathrm{Wu}$ et al., 2008). We used the 1.5-year flood as an evaluation of the bankfull discharges. In high-flow pulse periods, flows less than bankfull discharges but greater than low flows. It's general to use the 25th percentile flow as the minimum 'high pulse' discharge. In low flow periods, it is base flow in each month. The Tennant method, which is a common method, is used to determine seasonal eflows (Tennant, 1976). From Tennant's opinion, 10\% of average daily flow (ADF) is recommended as the minimum instantaneous flow to sustain short-term survival habitat and 30\% ADF is recommended as a base flow to sustain good habitat for most aquatic species. In this study, the base flow in flood periods is $30 \% \mathrm{ADF}$ and in non-flood periods is $10 \%$ ADF. In extreme low flow periods, flows equal to or less than the 95th percentile flow. This e-flow analysis has maintained flow variability as natural as possible in timing and magnitude to sustain the key natural ecological functions of ecosystems.

We use parameters I1, I2, I3 (I1 > I2 > I3) to divide the change of storage into four internals on behalf of different inflow conditions roughly corresponding to four flow periods: inflows greater than I1 (floods), inflows between I1 and I2 (high-flow pulses), inflows between I2 and I3 (base flows), and inflows less than I3 (extreme low flows). The parameters I1, I2, I3 are set equal to the values of bankfull discharges, 25 th percentile of all flows and the seasonal base flows (Yin et al., 2011, 2012).

While the flows are in different conditions, the e-flow requirements vary as followed (Yin et al., 2011, 2012):

(1) The inflow is greater than I1, the e-flow is equal to I1 to sustain flood-related ecological functions and the water released to downstream is no less than I1.

(2) The inflow is between I1 and I2, the e-flow is equal to the inflow.

(3) The inflow is between I 2 and I3, the e-flow is equal to the seasonal base flows.

(4) The inflow is less than I3, the e-flow is equal to the inflow

\subsection{Reservoir operating rule curves (RORCs)}

For a water supply reservoir, the reservoir operating rule curves (RORCs) is developed as shown in Figure 1. Reservoir is divided into four reservoir capacity zones by the three curves: the upper limit curve, the lower limit curve and the critical limit curves. The two curves are described by six parameters: two parameters describe the high and low storage zones and four parameters describe the initial and ending times of the linear transitions between the high and low storage. Here V only represents active storage.

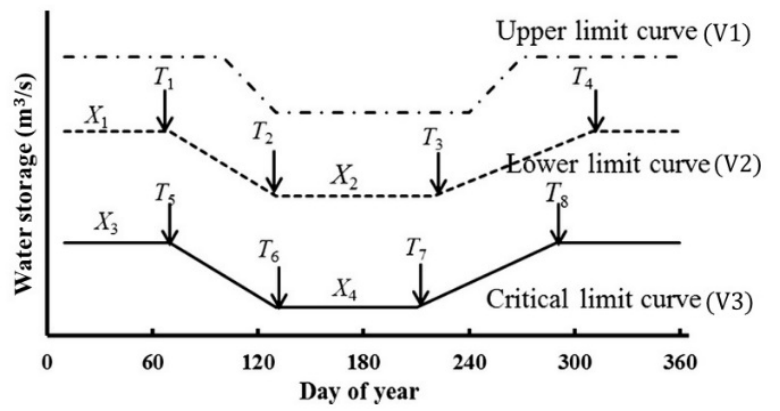

Figure 1. Typical reservoir operating rule curves. X1 and X2 represent the high and low storage zones for the lower limit curve; X3 and X4 represent the high and low storage zones for the critical limit curve; T1, T2, T3, and T4 represent the initial and ending times of the linear transitions between the high and low storage for the lower limit curve; T5, T6, T7, and T8 represent the initial and ending times of the linear transitions between the high and low storage for the critical limit curve.

\subsection{Reservoir operation objective, constraints and solution}

The main reservoir operation objective (L) was set to minimize the overall degree of the flow regime alteration (D) with constraint of the water supply reliability (P), as below:

$$
L=\min (D)
$$

$$
\text { Subject to: } \mathrm{P} \geq \mathrm{P}_{0}
$$

The water balance equation:

$$
V_{i}=V_{i-1}+\left(I_{i-1}-R_{i-1}-S_{i-1}\right) \Delta t_{i-1}-e_{i-1}
$$

where $\mathrm{V}_{\mathrm{i}}$ is reservoir storage at the beginning of time period $i$; $I_{i}$ is the water inflow of power station during time period $\mathrm{i} ; \mathrm{S}_{\mathrm{i}-1}$ is the spillage water of reservoir during time period $\mathrm{i} ; \triangle \mathrm{t}_{\mathrm{i}-1}$ is the length of time period $\mathrm{i}$; $\mathrm{e}_{\mathrm{i}-1}$ is the water losses from the reservoir in the form of seepage and evaporation and can be omitted in this study.

The constraints for $X_{i}(i=1,2,3,4)$ and $T_{j}(j=1,2, \ldots 8)$ and $\mathrm{a}, \mathrm{b}$ are as follows:

$$
\begin{gathered}
\mathrm{V}_{1}>\mathrm{X}_{1}>\mathrm{X}_{2} \\
\mathrm{~V}_{1}>\mathrm{X}_{1}>\mathrm{X}_{3} \\
\mathrm{X}_{2}>\mathrm{X}_{4}>0 \\
\mathrm{X}_{3}>\mathrm{X}_{4}>0 \\
1 \leq \mathrm{T}_{1}<\mathrm{T}_{2}<\mathrm{T}_{3}<\mathrm{T}_{4}<36 \\
1 \leq \mathrm{T}_{5}<\mathrm{T}_{6}<\mathrm{T}_{7}<\mathrm{T}_{8}<36 \\
0<\mathrm{a}<\mathrm{b}<1
\end{gathered}
$$

In this paper, the parameters to be optimized are $X_{i}, T_{j}$, $a$ and $b$, which greatly influence the value of $\mathrm{D}$ and $\mathrm{P}$. Genetic algorithms (GA), which is an efficient and robust solution for reservoir optimization problems (Louati et al., 
2011), is adopted to optimize these parameters to carry out our optimization results of reservoir operations.

We use the range of variability approach (RVA) to quantify the degree of alteration of ecological flow regime (Richter and Thomas, 2007). The RVA uses the variation degree of 32 indicators called indicators of hydrologic alternation (IHAs), which are categorized into five groups.

\section{Numerical experiments}

A hypothetical reservoir system is developed in this paper. Three kinds of parameters, including reservoir capacity, reservoir inflow and water supply yield, are analyzed in the hypothetical reservoir operation model to examine their effect on ecological flow regime.

The reservoir capacity (v) is represented by the active storage. The the reservoir capacity in this paper ranges from $0.001 \times 10^{8}$ to $10 \times 10^{8} \mathrm{~m}^{3}$. A 30 -year of inflow sequences $\mathrm{I}^{*}$ is generated by Thomas-Fiering model (Harms and Campbell, 1967). Other groups of inflow sequences are $\mathrm{k}$ ratios of $\mathrm{I}^{*}$. $\mathrm{k}$ ranges from 0.01 to 100 . According to China Water Resources Bulletin, urban average water consumption is $0.247 \mathrm{~m}^{3} /$ day. For a medium city with the population of 6.7 million (e.g. Dalian city), the projected water supply is about $38 \mathrm{~m}^{3} / \mathrm{s}$ for daytime. Thus, we take $50 \mathrm{~m}^{3} / \mathrm{s}$ as the base value of water supply. The range of water supply is $(0.01 \sim 100)$ $\times 50 \mathrm{~m}^{3} / \mathrm{s}$ and the $\mathrm{k}_{\mathrm{w}}$ ratio is range from 0.01 to 100 .

\section{Result analysis}

\subsection{The effect of different reservoir capacities on D}

In Figure 2(a), it compares the effect of different reservoir capacities on the average degree of flow regime alteration (D), with 50,250 or $500 \mathrm{~m}^{3} / \mathrm{s}$ of water supply and the base initial inflow sequences of reservoir inflow under Fourperiod release approach (FP).

From Figure 2(a), we can see that the shape of results of $\mathrm{D}$ is concave. When water supply and inflows keeps the same, with the increasing reservoir capacity in magnitude, D firstly decrease then increase, and achieve a minimum value at certain reservoir capacity. It demonstrates the importance of finding a proper reservoir capacity in reservoir design stage to better improve the ecological flow regime.

What's more, with the water supply increasing, the D is increasing. The result under $\mathrm{w}=50 \mathrm{~m}^{3} / \mathrm{s}$ has the lowest $\mathrm{D}$; The result under $\mathrm{w}=500 \mathrm{~m}^{3} / \mathrm{s}$ has the biggest $\mathrm{D}$, which is in line with reality. Besides, the variation trend of $\mathrm{D}$ under $\mathrm{w}=50$ and $250 \mathrm{~m}^{3} / \mathrm{s}$ is very small and almost keep a horizontal line. The the variation trend of $\mathrm{D}$ under $\mathrm{w}=500$ $\mathrm{m}^{3} / \mathrm{s}$ is distinct. Such results highlight that a higher water supply in reservoir optimization model may make ecological flow regime more sensitive to reservoir capacity.
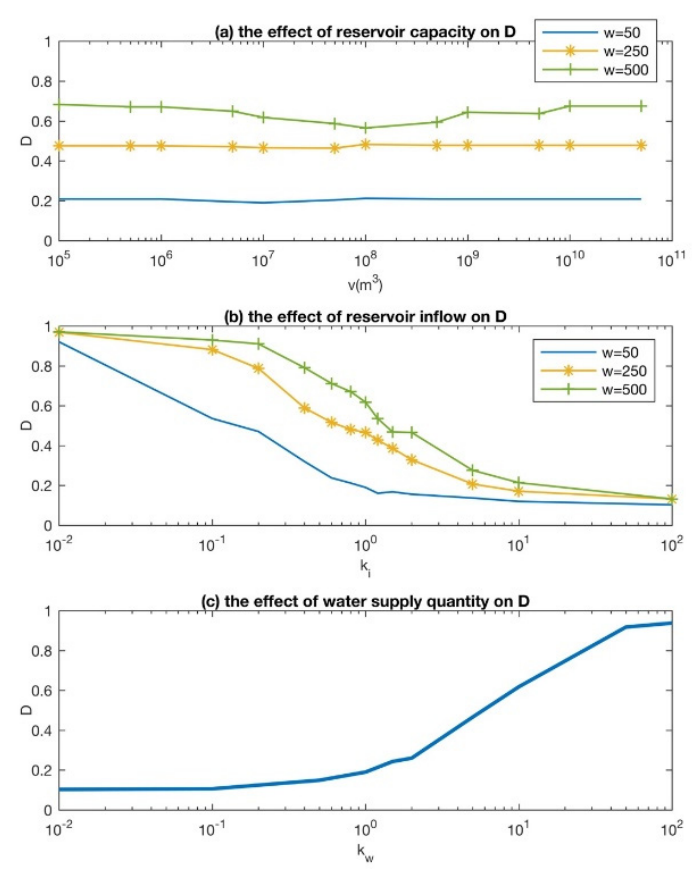

Figure 2. Results of D corresponding to different reservoir capacities, reservoir inflows and water supplies under different water supply quantities.

\subsection{The effect of different inflows on D}

In Figure 2(b), it compares the effect of different inflows on D, with 50,250 or $500 \mathrm{~m}^{3} / \mathrm{s}$ of water supply and $0.1 \times 10^{8} \mathrm{~m}^{3}$ of reservoir capacity under Four-period release approach (FP). The multi-year average daily inflow ranges from 18 to $1.8 \times 10^{5} \mathrm{~m}^{3} / \mathrm{s}$.

From Figure 2(a), we can see that the value of $D$ decreases monotonously with inflows. When reservoir capacity and water supply keep the same, with the increasing reservoir inflows multiply, the value of D initially falls quickly, and then decrease slowly. When $\mathrm{k}$ is enough small, the value of D almost keeps the same.

Besides, with inflows increasing, the $\mathrm{D}$ is decreasing. The result under $\mathrm{w}=50 \mathrm{~m}^{3} / \mathrm{s}$ has the lowest $\mathrm{D}$; The result under $\mathrm{w}=500 \mathrm{~m}^{3} / \mathrm{s}$ has the biggest $\mathrm{D}$, which is in line with 4.1 .

\subsection{The effect of different water supplies on D}

In Figure 2(c), it compares the effect of different water supplies on $\mathrm{D}$, with $0.1 \times 10^{8} \mathrm{~m}^{3}$ of reservoir capacity and the base initial inflow sequences of reservoir inflow under Four-period release approach (FP).

From Figure 2(a), we can see that the value of D increases monotonously with water supply. When reservoir capacity and inflows remain the same, with the increasing water supply multiply, the value of D initially remain stable, then increase slowly, and then increase rapidly, finally remain stable.

Besides, when $\mathrm{k}_{\mathrm{w}}$ is less than 0.1 , the value of $\mathrm{D}$ keep stable. It suggests that the different water supplies could not affect ecological flow regime. 


\section{Conclusion}

This paper is one of the first researches that try to generalize the impact of three kinds of parameters, including reservoir capacity, reservoir inflow and water supply yield, on ecological flow regime under Fourperiod release approach (FP). According to this paper, eflow management strategy has a great impact on the ecological flow regime. When water supply and inflows keeps the same, it is significant to find a proper reservoir capacity in reservoir design stage to better improve the ecological flow regime. Besides, a higher water supply in reservoir optimization model may make ecological flow regime more sensitive to reservoir capacity. The results also show that the existence of a reservoir inflow or a water supply yield that can make ecological flow regime small enough and with reservoir inflows of water supply yields increase, the ecological flow regime will not change.

\section{References}

1. R.M. Vogel, J. Sieber, S.A. Archfield, M.P. Smith, C.D. Apse, A. Huber-Lee, Relations among storage, yield, and instream flow. Water Resour. Res. 43 (2007).

2. D.E. Rheinheimer, P. Liu, S. Guo, Re-operating the Three Gorges Reservoir for Environmental Flows: A Preliminary Assessment of Trade-offs, River Res. Appl. 32: 257-266 (2016).

3. J.T. Shiau, F.C. Wu, Optimizing environmental flows for multiple reaches affected by a multipurpose reservoir system in Taiwan: Restoring natural flow regimes at multiple temporal scales. Water Resour. Res. 49: 565-584 (2013).

4. G.E. Petts, Instream Flow Science For Sustainable River Management. J. Am Water Resour. Assoc. 45: 1071-1086 (2009).

5. B.D. Richter, G.A. Thomas, Restoring Environmental Flows by Modifying Dam Operations. Ecol. Soc. 12(1) (2007).

6. W.P. Tsai, F.J. Chang, L.C. Chang, E.E. Herricks, AI techniques for optimizing multi-objective reservoir operation upon human and riverine ecosystem demands. J. Hydrol. 530: 634-644 (2015).

7. X.A. Yin, Z.F. Yang, G.E. Petts, Reservoir operating rules to sustain environmental flows in regulated rivers. Water Resour. Res. 47 (2011).

8. X.A. Yin, Z.F. Yang, G.E. Petts, OPTIMIZING ENVIRONMENTAL FLOWS BELOW DAMS. River Res. Appl. 28: 703-716 (2012).

9. D.L. Tennant, Instream flow regimens for fish, wildlife, recreation and related environmental resources. Fisheries 1(4): 6-10 (1976).

10. M.H. Louati, S. Benabdallah, F. Lebdi, D. Milutin, Application of a Genetic Algorithm for the Optimization of a Complex Reservoir System in Tunisia. Water Resour. Manag. 25: 2387-2404 (2011).
11. A.A. Harms, T.H. Campbell, An extension to the Thomas-Fiering Model for the sequential generation of streamflow. Water Resour. Res. 3: 653-661 (1967). 